\title{
Sharp Needle Recanalization: A Salvage Procedure for Failing Arteriovenous Fistula Due to Tight Uncrossable Venous Stenosis
}

\author{
Sultan R. Alharbi ${ }^{1}{ }^{10}$ \\ ${ }^{1}$ Department of Radiology and Medical Imaging, College of Medicine, \\ King Saud University, Riyadh, Kingdom of Saudi Arabia \\ Arab J Intervent Radiol 2021;5:114-115.
}

A 33-year- old male presented with malfunctioning brachiobasilic arteriovenous fistula (AVF) due to short tight juxta anastomotic stenosis ( $\mathbf{- F i g . 1}$ ). Access was gained into the AVF draining vein, and multiple trials to cross the

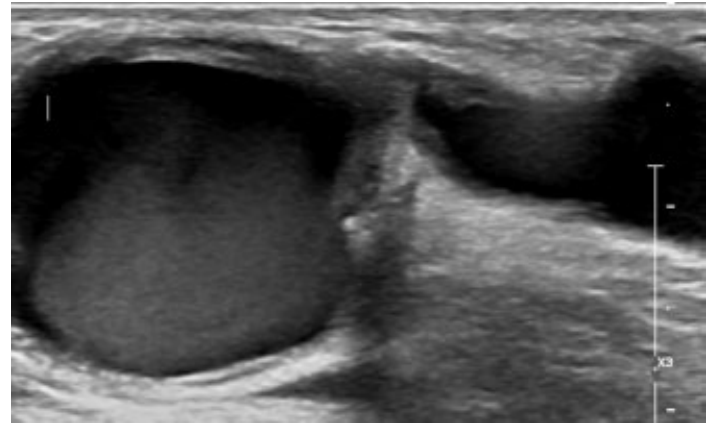

Fig. 1 Ultrasound of arteriovenous fistula (AVF) showing a juxta anastomotic tight stenosis and aneurysmal dilatation.
Address for correspondence Sultan R. Alharbi, MD, Department of Radiology and Medical Imaging, College of Medicine, King Saud University, P.O. Box 7805, Riyadh 11472, Kingdom of Saudi Arabia (e-mail: drsultan000@gmail.com).

tight stenosis using catheter and wire failed (-Fig. 2). Sharp needle recanalization was performed under ultrasound guidance, using $21 \mathrm{G}$ needle and wire to cross this tight stenosis (-Fig. 3a,b). Wire passed into the AVF

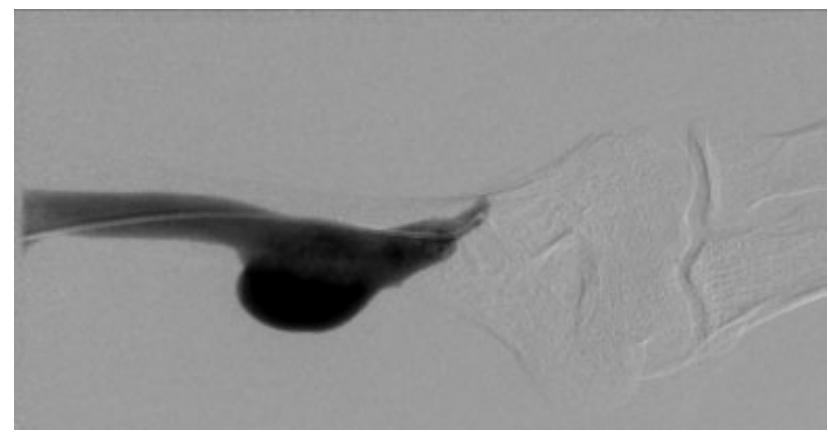

Fig. 2 Fistulogram showing patent arteriovenous fistula (AVF) with uncrossable tight stenosis.
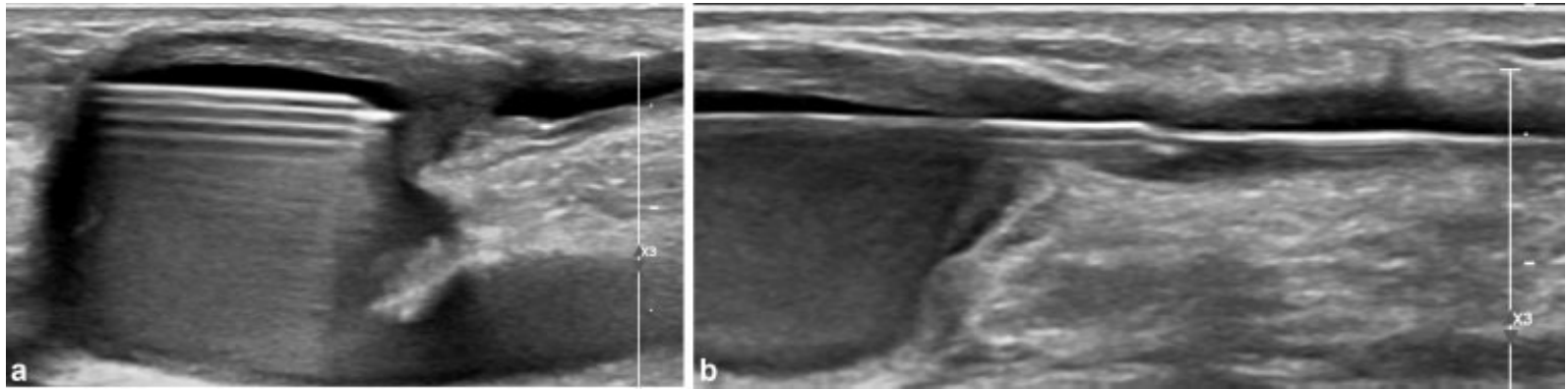

Fig. 3 (a and b) Ultrasound-guided sharp needle recanalization using 21G needle and wire.

published online

December 22, 2021
DOI https://doi.org/

$10.1055 / \mathrm{s}-0041-1739304$.

ISSN 2542-7075. (c) 2021. The Pan Arab Interventional Radiology Society. All rights reserved.

This is an open access article published by Thieme under the terms of the Creative Commons Attribution-NonDerivative-NonCommercial-License, permitting copying and reproduction so long as the original work is given appropriate credit. Contents may not be used for commercial purposes, or adapted, remixed, transformed or built upon. (https://creativecommons.org/ licenses/by-nc-nd/4.0/)

Thieme Medical and Scientific Publishers Pvt. Ltd., A-12, 2nd Floor, Sector 2, Noida-201301 UP, India 


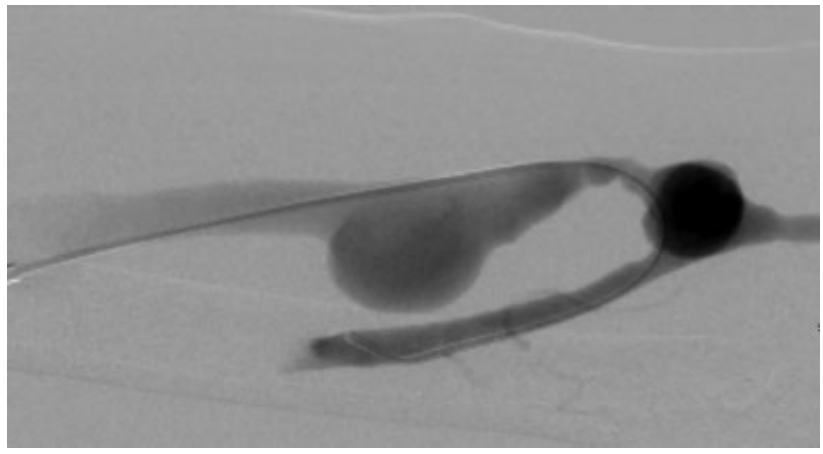

Fig. 4 Postballoon angioplasty fistulogram showing successful angioplasty without contrast extravasation.

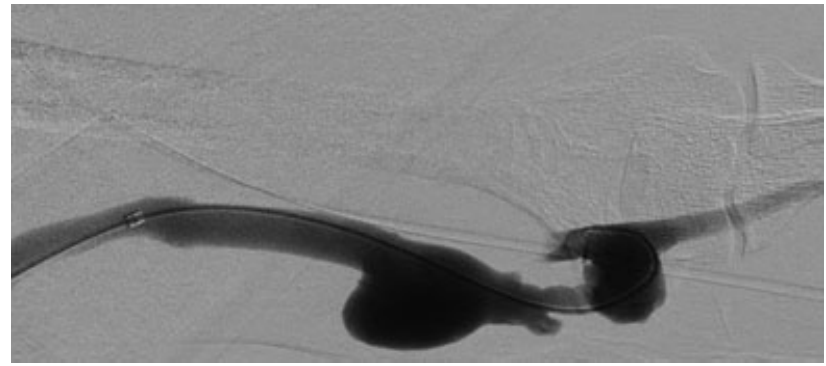

Fig. 5 Follow-up fistulogram after 2 years showing patent arteriovenous fistula (AVF).

draining vein and snared through the already placed vascular sheath. Balloon angioplasty was performed using 6-mm, high-pressure balloon and inflated for 3 minutes. Postangioplasty venogram showed successful result (-Fig. 4). Patient had follow-up fistulogram and angio- plasty every 6 months for 2 years, and fistula remained patent (-Fig. 5).

Sharp needle recanalization is a well-known technique for central venous occlusion. ${ }^{1}$ This technique is rarely used in peripheral veins. ${ }^{2}$ Jump graft is a salvage technique used to bridge stenotic/thrombotic venous segment of AVF. Jump graft is created surgically or percutaneously by a mean of stent graft for failing AVF. ${ }^{3}$ Sharp needle recanalization is a minimally invasive alternative salvage technique to surgical jump graft in tight uncrossable AVF peripheral venous stenosis. ${ }^{4}$

\section{Financial Support and Sponsorship}

Nil.

\section{Conflicts of Interest}

None declared.

\section{References}

1 Arabi M, Ahmed I, Mat'hami A, Ahmed D, Aslam N. Sharp central venous recanalization in hemodialysis patients: a single-institution experience. Cardiovasc Intervent Radiol 2016;39(06): 927-934

2 Miller GA, Koh E, Khariton A, et al. Sharp needle recanalization for salvaging hemodialysis accesses with chronically occluded peripheral outflow. J Vasc Access 2012;13(01):22-28

3 Timpone VM, Gover DD. Percutaneous creation of a jump bypass graft in a native arteriovenous hemodialysis fistula. J Vasc Interv Radiol 2011;22(05):734-736

4 Noh SY, Goo DE, Kim YJ, Yang SB, Lee JM, Lee WH. Sharp needle recanalization technique for peripheral hemodialysis arteriovenous fistula occlusion. Cardiovasc Intervent Radiol 2021 (e-pub ahead of print). Doi: 10.1007/s00270-021-02809-1 